\title{
Pathological recognition of cardiomyopathy
}

\author{
E. G. J. Olsen \\ M.D. \\ Department of Morbid Anatomy and Histopathology, National Heart Hospital,
and Cardiothoracic Institute, University of London
}

UsING the classification employed in the preceding paper, for each type of cardiomyopathy a pathological counterpart exists. This communication summarizes the salient features which permit recognition of the various types of cardiomyopathy. They have been described by many workers in recent years and have been reviewed by this author in $1972(a, b)$ and 1973.

\section{Congestive cardiomyopathy}

This condition is of world-wide distribution and has been described under many synonyms, which were reviewed by Cockshott, Thorpe and Ikeme in 1967.

The macroscopic features are an overweight heart (up to $750 \mathrm{~g}$ ), severe dilatation of all chambers and flabby myocardium without any abnormality in valves or septae. Non-specific endocardial thickening is often found and thrombus may or may not be superimposed. Patchy fibrosis, limited to the inner third of the myocardium, may also be present. The coronary arteries are generally normal.

Histological examination shows regularly arranged myocardial fibres of apparently normal dimension due to attenuation, but showing nuclear changes of hypertrophy, such as pyknosis, blunting or vesicular changes (Fig. 1a). Small foci of necrosis and small accumulation of chronic inflammatory cells are occasionally found (Goodwin et al., 1961). Small vessels in over sixty cases personally examined have

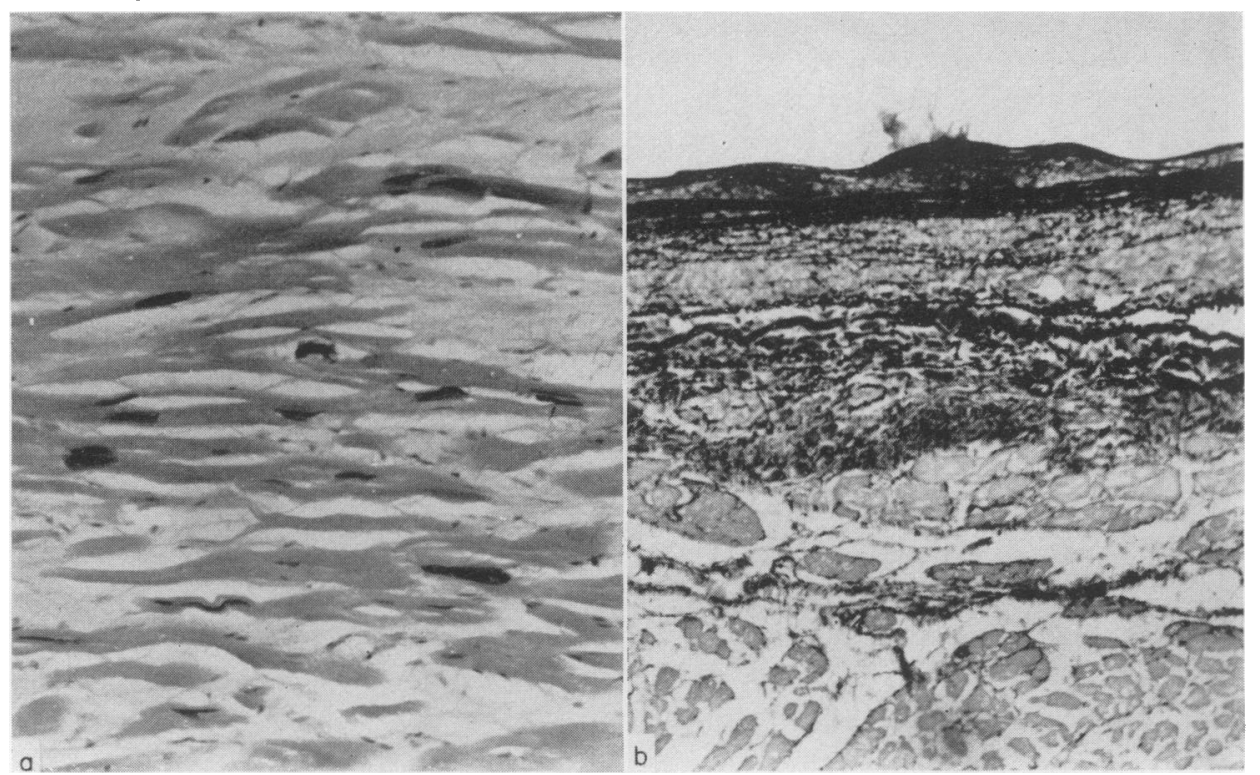

Fig. 1. (a) Regularly arranged myocardial fibres with nuclear changes of hypertrophy are shown. The fibres are of apparently normal diameter, which is due to their attenuation. Some fibrous replacement of muscle cells can be seen. (From the inner third of the left ventricular wall from a patient with congestive cardiomyopathy.) $\mathrm{HE} \times 250$. (b) A prominent smooth muscle layer can be seen in the thickened endocardium of the right ventricle. This denotes dilatation of the chamber. From the same patient as Fig. 1a. Weigert's elastic van Gieson $\times 160$. 
not shown any abnormalities. The overlying endocardium is thickened with an often prominent increase of the smooth muscle component which denotes severe dilatation of some duration (Fig. 1b).

Histochemically, changes consist of an apparent patchy increase in enzyme systems such as succinic dehydrogenase reflecting an increased number of mitochondria, acid phosphatase and non-specific esterases, reflecting an increased number of lysosomes. Glycogen is also increased (van Noorden, 1971; Olsen, personal observations, 1973).

Electronmicroscopic appearances similarly show no distinguishing features other than those of hypertrophy (Fig. 2). Increase in glycogen is confirmed at this level of investigation.

\section{Hypertrophic cardiomyopathy (with or without ob- struction)}

In 1958, Teare drew attention to the pathology of this condition. The heart is usually only slightly enlarged, often globular in shape and overweight. The pathognomonic change is asymmetric hypertrophy of the interventricular septum, which may exceed double the measurement in thickness of the remaining parts of the left ventricular wall (Fig. 3). In this asymmetric area, the abnormally arranged myocardial fibres are located, which may extend to a variable distance into the adjacent anterior or posterior walls of the left ventricle. The deep bulbospiral muscle is involved and the superficial bulbospiral and superficial sinospiral muscle lining the left ventricular cavity, or the deep sinospiral muscle lining the right ventricular cavity, may become very thin, so that the abnormal myocardial fibres may reach the endocardium. Papillary muscles may be displaced as a result of interventricular septal hypertrophy and anatomic rotation of the anterior mitral valve leaflet has occasionally been found (Björk, Hultquist and Lodin, 1961 ; Björk, 1964).

Histologically, highly characteristic features are evident. The normal regular arrangement of myocardial fibres is lacking: fibres appear to run in all directions, and appear to be short (Fig. 4). The myocardial fibres are often extremely hypertrophied (by as much as $100 \mu$ in diameter) and are interrupted by fibrous tissue. Nuclei are often bizarre in shape and may be surrounded by a clear zone, the socalled 'perinuclear halo'. The adjacent fibrils usually

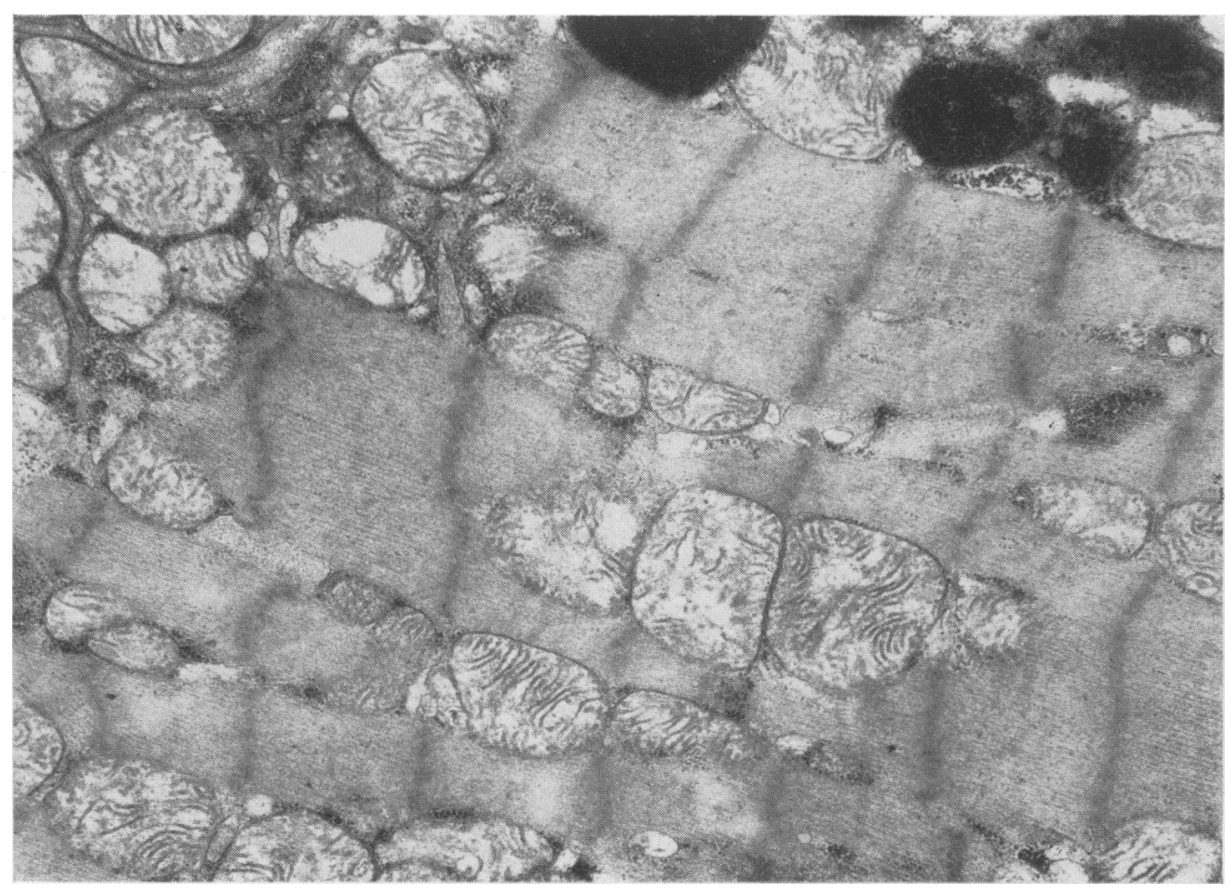

FIG. 2. Electronmicrograph from a patient with congestive cardiomyopathy, showing regularly arranged myofibrils and an increase of mitochondria, some of which show cristolysis. An increase of lipofuscin granules is also present (top right). Lead citrate and uranyl acetate $\times 12,600$. 


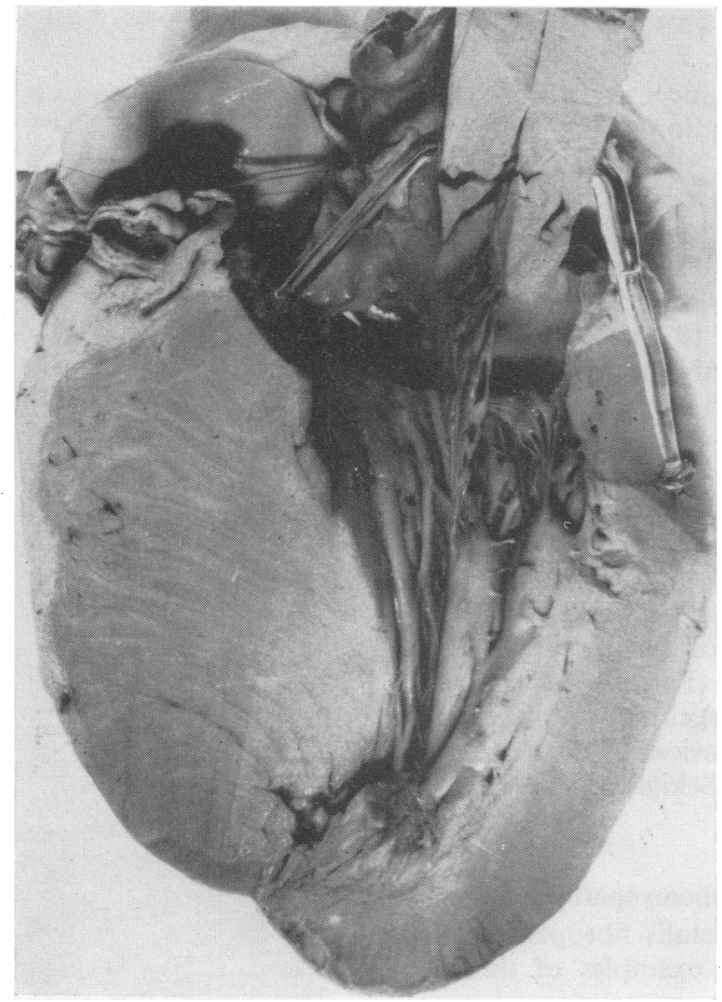

FIG. 3. The left ventricle has been opened and sectioned to show the extreme thickening of the interventricular septum (compare with the thickness of the free wall). This asymmetric hypertrophy is pathognomonic of hypertrophic obstructive cardiomyopathy. From the Reginald Hudson Museum, Cardiothoracic Institute.

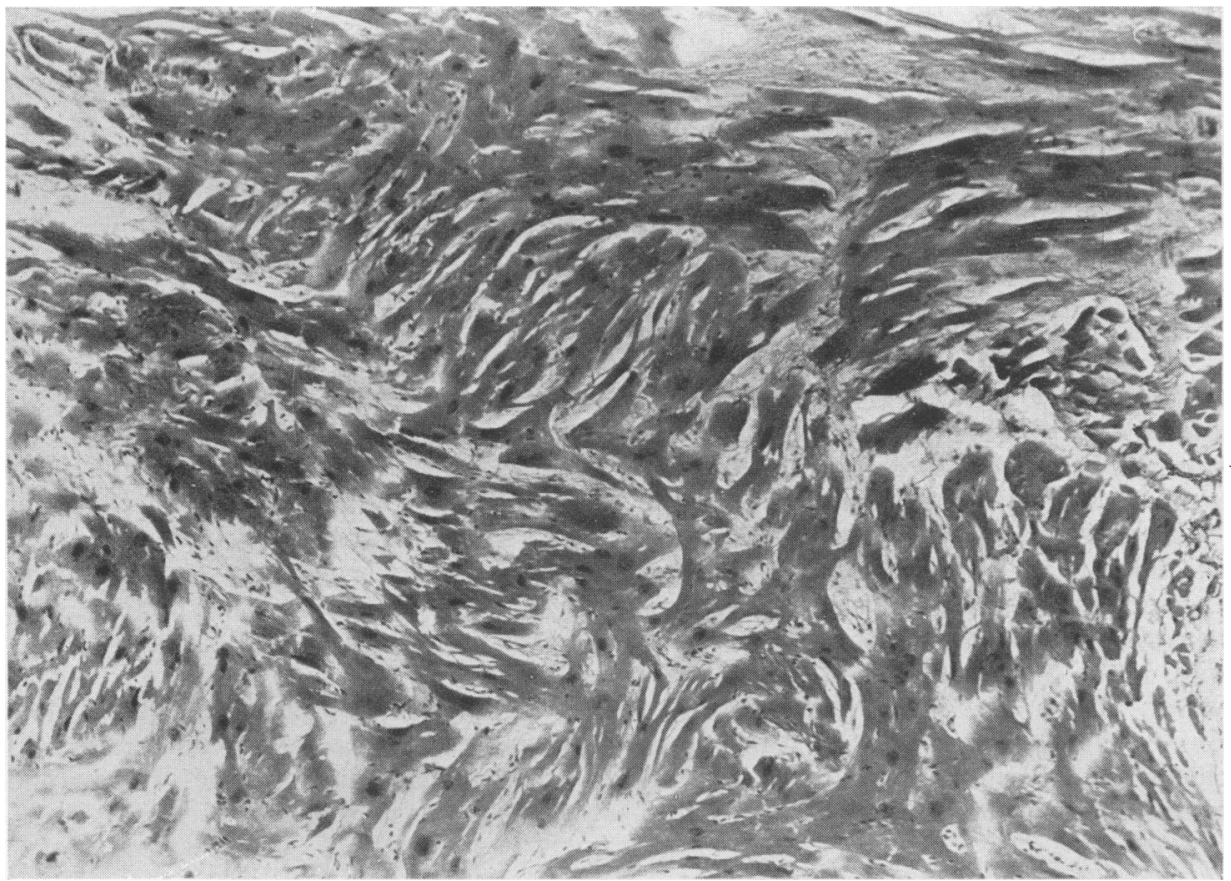

FIG. 4. Photomicrograph of tissue from the interventricular septum shown in Fig. 3. Normal, regular arrangement of myocardial fibres is totally lost; some of these fibres are severely hypertrophied. HE $\times 140$. 
have a 'moth-eaten' appearance. Another characteristic feature is whorl formation of the myocardial fibres.

An immense increase in glycogen, particularly in the perinuclear halo, has been found to be of diagnostic value in all the histochemical analyses undertaken (van Noorden, Olsen and Pearse, 1971; van Noorden and Pearse, 1971). Other enzyme systems may also be apparently increased, reflecting the severe hypertrophy which is present.

Ultrastructurally, there is derangement of the regularly arranged myofibrils which, like the fibres, on histological examination, appear to run in all directions. There is a severe increase in mitochondria in some areas, the so-called 'mitochondriosis'; an increase in lipofuscin granules is also found. Increased cellular branching of fibrils and $Z$ band changes have been described (Ferrans, Morrow and Roberts, 1972). All these changes may not necessarily be present and they have occasionally been observed in 'ordinary' hypertrophy (Sekiguchi et al., 1972, 1973).

\section{Restrictive or obliterative cardiomyopathy}

Löffler's endocarditis parietalis fibroplastica and endomyocardial fibrosis are examples of this rare type of cardiomyopathy.

\section{Löffler's endocarditis parietalis fibroplastica}

In this condition, the pathognomonic features include often extreme thickening of the endocardium of the ventricular cavities. Thrombus is frequently superimposed, which may on occasion fill the ventricular cavity.

Histologically, the extremely thick endocardium consists of collagen and elastic tissue and, not infrequently, a granulation tissue layer in which dilated blood vessels and lymphatic channels can be observed. An inflammatory infiltrate, containing varying numbers of eosinophils, is evident. Arteritis of the small vessels in the myocardium may or may not be present (Löffler, 1936; Weiss-Carmine, 1957).

\section{Endomyocardial fibrosis}

The pathology of this condition was first detailed by Davies in 1948, and the macroscopic changes are similar to the last mentioned condition, where extreme thickening of the endocardium is again evident. At one time it was believed that the inflow tract, apex, and only a small area of the outflow tract was involved, often ending in a thick rolled edge (Davies, 1968). Shaper, Hutt and Coles (1968) have, however, shown that five different types of distribution of endocardial thickening can occur, which includes involvement of the outflow tract of the left ventricle. Both ventricles may be involved in

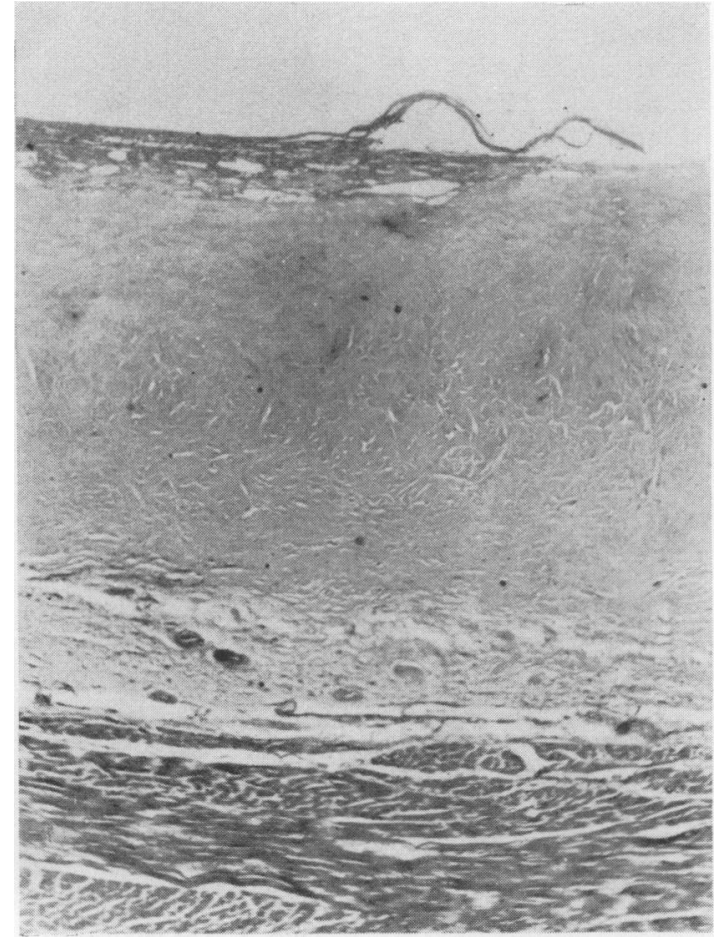

FIG. 5. The extremely thickened endocardium is arranged in zones. Organizing thrombus overlies predominantly hyaline collagen tissue. The zone adjacent to the myocardium is the granulation tissue zone, in which many blood vessels can be seen. From a patient with endomyocardial fibrosis. $\mathrm{HE} \times \mathbf{4 0}$.

the same patient. Thrombus may be superimposed in about half the cases.

Histochemically, zonal differentiation of the thickened endocardium is characteristic (Fig. 5). Beneath the thrombus, when present, a hyaline collagen tissue layer is found in which areas of calcification may be present. Beneath this layer cellular fibrous tissue is often evident. The deepest zone, adjacent to the myocardium, is the granulation tissue layer, which resembles that of Löffler's endocarditis. Eosinophils may occasionally be found. Arteritis is usually not present. Brockington and Olsen in 1973 suggested that Löffler's endocarditis and endomyocardial fibrosis may represent different stages of the same disease process, the origin of which can be traced to the presence of eosinophils in the myocardium.

Summarizing: congestive cardiomyopathy can be diagnosed by the severe dilatation of the hypertrophied heart and absence of any abnormality of either valves or septae. 
Hypertrophic cardiomyopathy is characterized by the asymmetric hypertrophy and the typical histological appearances confirmed by certain histochemical and ultrastructural changes.

Löffler's endocarditis and endomyocardial fibrosis are recognized by extreme thickening of the endocardium with characteristic layering on histological examination.

\section{References}

Bü̈r, V.O., Hultquist, G. \& Lodin, H. (1961) Subaortic stenosis produced by an abnormally placed anterior mitral valve leaflet. Journal of Thoracic and Cardiovascular Surgery, 41, 659.

BJörK, V.O. (1964) In: Cardiomyopathies, p. 127. Ciba Foundation Symposium, Churchill, London.

Brockington, I.F. \& Olsen, E.G.J. (1973) Löffler's Endocarditis and Davies' Endomyocardial Fibrosis. American Heart Journal, 85, 308.

CockshotT, W.P., Thorpe, G.J. \& IKeme, A.C. (1967) Radiological aspects of heart muscle disease in Nigerian adults. Circulation, 36, 460.

DAVIES, J.N.P. (1948) Endocardial fibrosis in Africans. East African Medical Journal, 25, 10.

DAviES, J.N.P. (1968) The ridge in endomyocardial fibrosis. Lancet, i, 631.

Ferrans, V.J., Morrow, A.G. \& Roberts, W.C. (1972) Myocardial ultrastructure in idiopathic hypertrophic subaortic stenosis. A study of operatively excised left ventricular outflow tract muscle in 14 patients. Circulation, 45, 769.

Goodwin, J.F., Gordon, H., Hollman, A. \& Bishop, M.B. (1961) Clinical aspects of cardiomyopathy. British Medical Journal, i, 69.
LÖFFLER, W. (1936) Endocarditis parietalis fibroplastica mit Bluteosinophilie ein eigenartiges Krankheitsbild. Schweizerische medizinische Wochenschrift, 17, 817.

Olsen, E.G.J. (1972a) Pathology of primary cardiomyopathies. Postgraduate Medical Journal, 48, 732.

OLSEN, E.G.J. (1972b) Cardiomyopathies. In: Cardiovascular Clinics, 4, No. 2 (Ed. by A. N. Brest and J. E. Edwards), p. 240. F. A. Davis, Philadelphia.

Olsen, E.G.J. (1973) In: The Pathology of the Heart, p. 171. Intercontinental Medical Book Corporation, New York, N.Y.

Sekiguchi, M., Konno, S., Hasegawa, F. \& Hirosawa, K. (1972/73) Some characteristic electron microscopic pictures of diseased myocardium obtained by endomycardial biopsies. Bulletin of the Heart Institute Japan, XIV, 30.

ShaPeR, A.G., Hutt, M.S.R. \& Coles, R.M. (1968) Necropsy study of endomyocardial fibrosis and rheumatic heart disease in Uganda, 1950-65. British Heart Journal, 30, 391.

Teare, D. (1958) Asymmetrical hypertrophy of the heart in young adults. British Heart Journal, $20,1$.

Van Noorden, Susan (1971) Personal communication.

Van Noorden, Susan, Olsen, E.G.J. \& Pearse, A.G.E. (1971) Hypertrophic obstructive cardiomyopathy: A histological, histochemical and ultrastructural study of biopsy material. Cardiovascular Research, V, 118.

Van Noorden, Susan \& Pearse, A.G.E. (1971) Histochemistry and electron microscopy of the heart in hypertrophic obstructive cardiomyopathy. In: Hypertrophic Obstructive Cardiomyopathy, p. 192. Ciba Foundation Study Group No. 37, Churchill, London.

Weiss-CARmine, S. (1957) Die Endocarditis parietalis fibroplastica mit Bluteosinophilie (Löffler) und ihre Stellung im Rahmen der parietalendokarden Fibrosen. Schweizerische medizinische Wochenschrift, 87, 890. 